\title{
Identification of Constraining Experimental-Design Factors in Mycorrhizal Pot-Growth Studies
}

\author{
Patrick Audet and Christiane Charest \\ Department of Biology, Ottawa Carleton Institute of Biology, University of Ottawa, 30 Marie Curie, Ottawa, ON, Canada K1N 6N5 \\ Correspondence should be addressed to Patrick Audet, paude086@uottawa.ca
}

Received 14 January 2010; Revised 14 March 2010; Accepted 7 April 2010

Academic Editor: Zed Rengel

Copyright (๑) 2010 P. Audet and C. Charest. This is an open access article distributed under the Creative Commons Attribution License, which permits unrestricted use, distribution, and reproduction in any medium, provided the original work is properly cited.

In the objective of testing the design of pot-growth experiments, we conducted two greenhouse studies of a "dwarf" sunflower cultivar and an arbuscular mycorrhizal (AM) fungus to determine how pot size and inoculum distribution affect plant growth and AM symbiosis. As predicted, large-potted plants developed a greater overall biomass and root colonization than smallpotted ones which we attributed to the larger "rootable" volume. Furthermore, plants grown in a band of high density inoculum substrate showed a higher prevalence of fungal vesicles (sites of lipid storage) indicating a more advanced level of root colonization compared to those grown in a dispersed inoculum substrate; this likely being due to the higher frequency of interaction between roots and fungal propagules. In a second experiment, large-potted AM plants showed a greater tolerance to water deficit than non-AM control plants; however, this mycorrhizal effect was not detected among small-potted plants. We conclude that careful consideration should be made toward design parameters to limit result biases and ultimately facilitate comparison of findings between studies.

\section{Introduction}

Studies involving pot-grown plants represent an underpinning of comparative plant physiology. However, design parameters such as the size of the experimental microcosm (e.g., pot size) may confound the interpretation of results regardless of the intended experimental conditioning [14]. Specific to the study of mycorrhiza-a mutualistic association between plant roots and soil fungi-we believe that the pot size and fungal inoculum distribution may inadvertently affect plant growth and symbiotic interaction. It can be hypothesized that pot size influences the dynamics of resource allocation and mycorrhizal symbiosis by potentially restricting the proliferation of roots and extraradical hyphae [5]. Meanwhile, the distribution of fungal inoculum may also influence the frequency of interaction between roots and fungal propagules which then affects the level of root colonization and symbiotic activity [6]. To test these notions, we conducted a factorial greenhouse study of "dwarf" sunflower and an arbuscular mycorrhizal (AM) fungus to discern how the pot size and fungal inoculum distribution affect plant growth and root colonization. Given that the AM symbiosis is widely recognized for benefiting plants under various environmentally stressful conditions [7-11], we then conducted a follow-up experiment incorporating a water deficit treatment to investigate the effects of pot size on the dynamics of symbiotic association and stress tolerance. By identifying key design factors that influence plant growth and mycorrhizal association, it is our goal to improve upon the design of pot-growth experiments to facilitate a more effective comparison of findings between studies.

\section{Materials and Methods}

2.1. Experimental Design. In the first pot experiment, "dwarf" sunflower (Helianthus annuus L. var. Pacino) plants were grown from seeds (McKenzie Seeds, Brandon, MB, Canada) for 10 weeks in a previously autoclaved, low mineral soil mixture (sand:potting soil, 1:1 v/v). Plants were grown in either small $(2 \mathrm{~L})$ or large-sized $(7.5 \mathrm{~L})$ pots containing the same base soil mixture but incorporating 


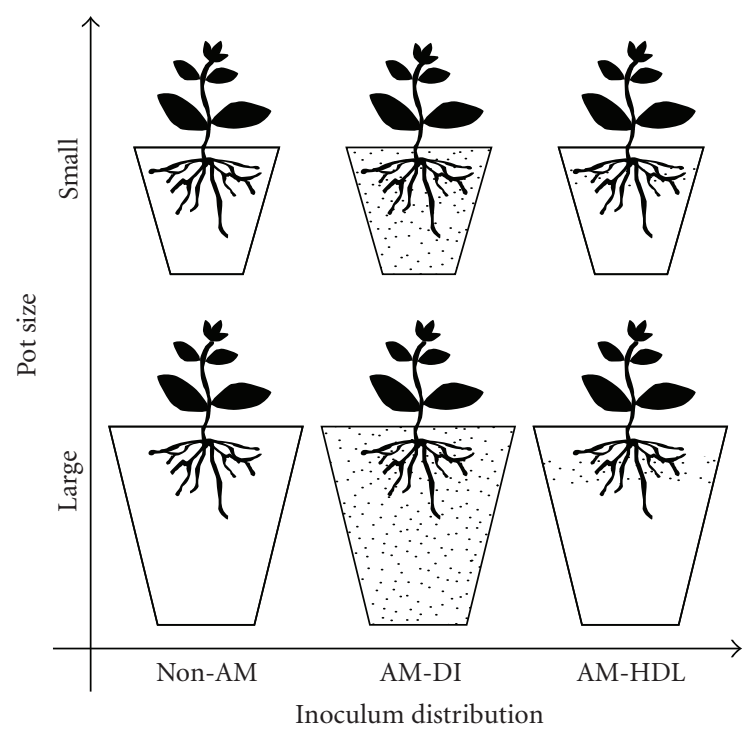

FIGURE 1: Schematization of the pot size and inoculum distribution treatments.

one of three fungal inoculum treatments (noninoculated [Control], dispersed inoculum [AM-DI], or high density layered inoculum [AM-HDL]) which resulted in a total soil volume equivalent to the respective pot size capacity (Figure 1). To test the effects of fungal inoculum distribution, the AM-soil treatments were achieved by incorporating fungal propagules (e.g., spores and hyphae) of Glomus intraradices Schenck \& Smith (isolate DAOM-181602) from a commercial inoculum having a reported density of 15 propagules $\mathrm{g}^{-1}$ dry substrate (Myke Pro Endo, Premier Tech, Premier Tech, Rivière-du-Loup, QC, Canada). The AMDI treatment consisted of the inoculum substrate being evenly mixed into the soil using an industrial mixer, whereas the AM-HDL treatment consisted of the same inoculum integrated as a $3 \mathrm{~cm}$ layer of substrate. Due to the respective pot-size volumes, it was estimated that small pots contained $\sim 750-1000$ total propagules (65 g inoculum substrate dose) while large pots contained $\sim 2750-3000$ propagules (200 g inoculum substrate dose). The factorial design of the study (1 plant sp. $\times 3$ soil treatments [Control; AM-DI; AM-HDL] $\times 2$ pot sizes [Small; Large] $\times 5$ reps) provided a total of 30 plants ( 1 plant per pot), each distributed in a factorial block design. The greenhouse conditions were maintained at $25^{\circ} \mathrm{C} / 23^{\circ} \mathrm{C}$ (day/night) with a 16 -hour photoperiod, an average light intensity of $364.2 \mu \mathrm{mol} \mathrm{m}^{-2} \mathrm{~s}^{-1}$, and a $65 \%$ relative humidity. Over the course of the experimental period, all plants were watered daily as required avoiding any leaching and fertilized biweekly (100 $\mathrm{ml}$ per week) from weeks 4 to 10 using a low phosphorus Long-Ashton nutrient solution $\left(\mathrm{K}_{2} \mathrm{SO}_{4} 2.0 \mathrm{mM}, \mathrm{CaCl}_{2}\right.$ anhydride $4.0 \mathrm{mM}, \mathrm{MgSO}_{4}$. $7 \mathrm{H}_{2} \mathrm{O} 1.5 \mathrm{mM}, \mathrm{NaH}_{2} \mathrm{PO}_{4} \cdot \mathrm{H}_{2} \mathrm{O} 1.5 \mathrm{mM}, \mathrm{NH}_{4} \mathrm{NO}_{3} 5.0 \mu \mathrm{M}$, $\mathrm{MnSO}_{4} \cdot 4 \mathrm{H}_{2} \mathrm{O} 0.01 \mathrm{mM}, \mathrm{CuSO}_{4} \cdot 5 \mathrm{H}_{2} \mathrm{O} 1.0 \mu \mathrm{M}, \mathrm{ZnSO}_{4}$. $7 \mathrm{H}_{2} \mathrm{O} 1.0 \mu \mathrm{M}, \mathrm{H}_{3} \mathrm{BO}_{3} 0.05 \mathrm{mM}, \mathrm{NaCl} 0.09 \mathrm{mM}, \mathrm{Na}_{2} \mathrm{MoO}_{4}$. $2 \mathrm{H}_{2} \mathrm{O} 0.5 \mu \mathrm{M}$, and EDTA-Fe $0.1 \mathrm{mM}$ ).

In the second experiment, plants were grown in similar small and large-sized pots containing either the non-AM control or AM-HDL inoculum substrates for 10 weeks under the same conditions as described above, but also incorporating a water deficit regime according to Ray and Sinclair [3]. This regime consisted of monitoring the water content of all soils via time-domain reflectometry [12], and specifically reducing the relative soil moisture from $90 \%$ to $20 \%$ for the drought-treated plants over the course of weeks 4 to 10 . All plants received a biweekly fertilization $(100 \mathrm{~mL}$ per week) as described above. The factorial design of the study $(1$ plant sp. $\times 2$ soil treatments [Control; AM-HDL] $\times 2$ pot sizes [Small; Large] $\times 2$ irrigation treatments [Well-Watered; Droughted] $\times 5$ reps) provided a total of 40 plants ( 1 plant per pot).

2.2. Harvest and Determination of Root Colonization. Plants were harvested 10 weeks after seeding with roots being thoroughly cleaned with tap water. Plant organs were then partitioned as roots, shoots, or flowers, oven-dried at $70^{\circ} \mathrm{C}$ for $72 \mathrm{~h}$, and weighed separately. At the time of harvest, fresh root samples $(2 \mathrm{~g})$ from each replicate were carefully excised from the apical zone near the taproot and stained with aniline blue $0.02 \%$ dye solution $(6.78 \mathrm{mM}$ aniline blue; $500 \mathrm{ml}$ glycerol; $450 \mathrm{ml} \mathrm{H}_{2} \mathrm{Od}$; $50 \mathrm{ml} 1 \% \mathrm{HCl}$ ) according to Dalpé [13]. One hundred, $\sim 1-2 \mathrm{~cm}$ long, root segments per replicate were randomly selected, mounted on slides, and examined at 100x and 400x magnification using a compound microscope (CX41, Olympus Inc., Centre-Valley, PA, USA). Samples of non-AM roots were also prepared to ensure their nonmycorrhizal status. Mycorrhizal colonization was estimated by determining the \% frequency of colonization [13], \% length of root colonization [14], and relative density (\# $\mathrm{mm}^{-1}$ root length) of fungal structures (e.g., intraradical vesicles and arbuscules). The equations for the $\%$ frequency (1), \% length of root colonization (2), and relative density (3) are defined as:

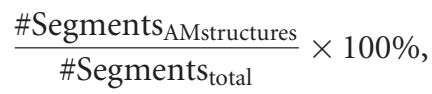

$$
\begin{aligned}
& \frac{\text { RootLength }_{\mathrm{AMstructure}}}{\text { RootLength }_{\text {total }}} \times 100 \% \text {, } \\
& \frac{\text { \#AMstructures }}{\text { RootLength }_{\text {colonized }}} \text {. }
\end{aligned}
$$

2.3. Statistical Analyses. One- and multi-way analyses of variance (ANOVA) with Bonferonni and Scheffé studentized range tests were performed for mean comparison analyses [15]. The Kolmogorov- Schmirnoff and Levene's tests were used, respectively, to verify the normality of distribution and homogeneity of residual variance. The data were Logtransformed as required to meet the assumptions of parametric analyses. All of the Fisher statistics (F), degrees of freedom (df), and $P$-value estimates were calculated using S-Plus 8.0 statistical software (Insightful Corp., Seattle, WA, USA). 


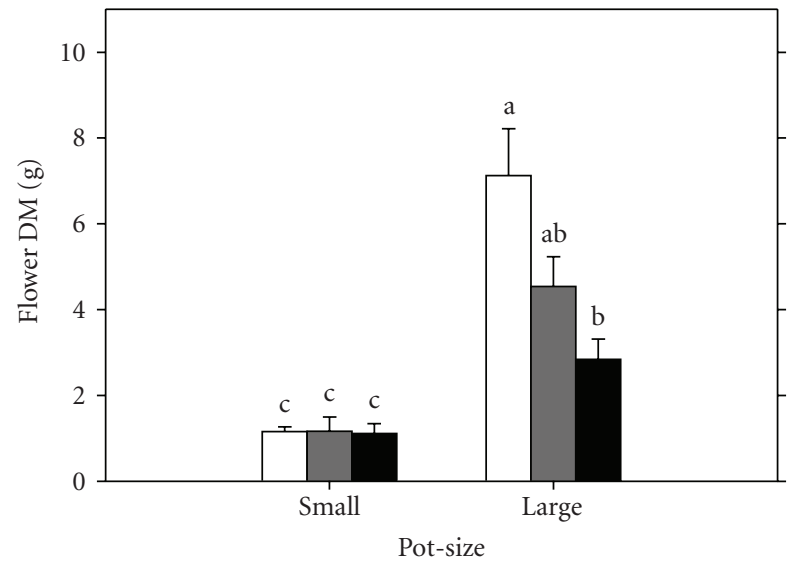

(a)

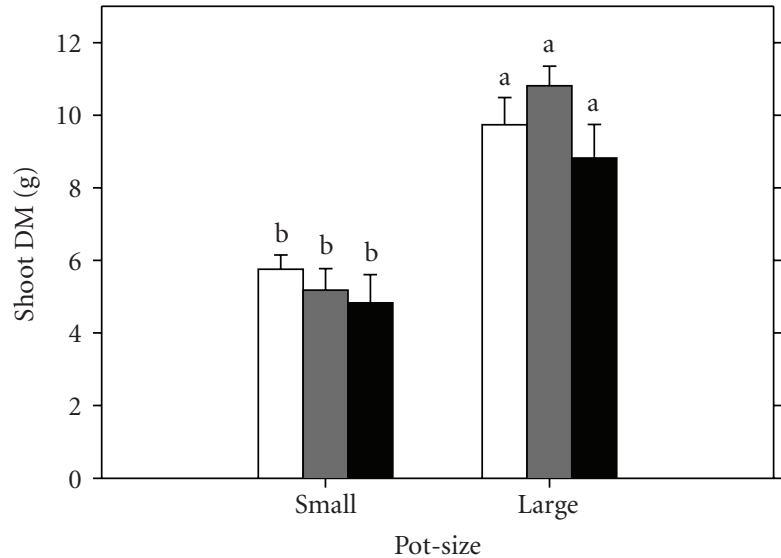

(b)
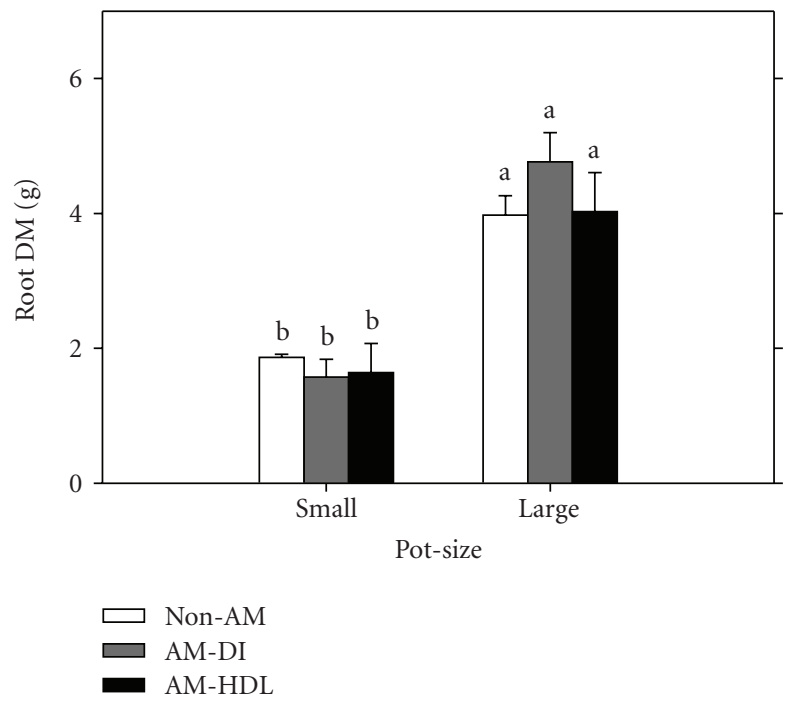

(c)

Figure 2: Flower (a), shoot (b), and root (c) dry masses from the pot size and inoculum distribution experiment. Means ( $n=5)$ and SE for the non-AM (empty bars), AM-DI (grey bars), and AM-HDL treatments (solid bars) are shown. Shared letters indicate treatments that are not significantly different according to Bonferonni and Scheffé mean comparison tests.

TABLE 1: Root colonization summary for the pot size and inoculum distribution experiment.

\begin{tabular}{|c|c|c|c|c|c|c|c|c|c|}
\hline \multirow[b]{2}{*}{ Pot size } & \multirow[b]{2}{*}{ Inoculum } & \multicolumn{3}{|c|}{ Frequency $(\%)$} & \multicolumn{3}{|c|}{ Root Length Colonized (\%) } & \multicolumn{2}{|c|}{ Density $\left(\mathrm{mm}^{-1}\right)$} \\
\hline & & Hyphae & Vesicles & Arbuscules & Hyphae & Vesicles & Arbuscules & Vesicles & Arbuscules \\
\hline \multirow[t]{2}{*}{ Small } & AM-DI & $21.0(3.1) \mathrm{b}$ & $7.4(1.0) \mathrm{c}$ & $21.0(3.1) b$ & $64.5(3.9) \mathrm{a}$ & $8.7(3.1) \mathrm{c}$ & $56.0(4.1) \mathrm{a}$ & $1.5(0.5) b$ & $7.0(0.6) \mathrm{a}$ \\
\hline & AM-HDL & $22.8(2.6) \mathrm{b}$ & $14.8(2.3) \mathrm{bc}$ & $20.0(2.5) b$ & $76.8(3.1) \mathrm{a}$ & $35.0(5.2) \mathrm{a}$ & $59.1(5.9) \mathrm{a}$ & $3.0(0.2) \mathrm{ab}$ & $4.4(0.3) \mathrm{b}$ \\
\hline \multirow[t]{2}{*}{ Large } & AM-DI & $40.0(4.1) \mathrm{a}$ & $20.0(2.7) \mathrm{b}$ & $39.0(3.5) \mathrm{a}$ & $75.3(4.5) \mathrm{a}$ & $14.2(2.2) \mathrm{b}$ & $58.9(4.5) \mathrm{a}$ & $2.2(0.1) \mathrm{b}$ & $7.0(0.7) \mathrm{a}$ \\
\hline & AM-HDL & $43.0(4.4) \mathrm{a}$ & $37(3.8) \mathrm{a}$ & $34.5(3.5) \mathrm{a}$ & $82.1(5.1) \mathrm{a}$ & $50.1(6.1) \mathrm{a}$ & $53.4(6.0) \mathrm{a}$ & $4.9(0.6) \mathrm{a}$ & $3.8(0.3) \mathrm{b}$ \\
\hline \multicolumn{10}{|c|}{ F-values and levels of significance } \\
\hline & Pot size $(\mathrm{P})$ & $34.9^{* * *}$ & $49.6^{* * *}$ & $28.2^{* * *}$ & $3.3 \mathrm{~ns}$ & $5.8^{*}$ & $0.4 \mathrm{~ns}$ & $0.3 \mathrm{~ns}$ & $1.85 \mathrm{~ns}$ \\
\hline & Inoculum (In) & $0.5 \mathrm{~ns}$ & $24.3^{* * *}$ & $0.8 \mathrm{~ns}$ & $4.7^{*}$ & $51.2^{* * *}$ & $0.1 \mathrm{~ns}$ & $33.3^{* * *}$ & $25.6^{* * *}$ \\
\hline & PxIn & $0.1 \mathrm{~ns}$ & $4.8^{*}$ & $0.3 \mathrm{~ns}$ & $0.4 \mathrm{~ns}$ & $1.1 \mathrm{~ns}$ & $0.6 \mathrm{~ns}$ & $0.4 \mathrm{~ns}$ & $9.4^{* *}$ \\
\hline & Block & $3.2 \mathrm{~ns}$ & $3.6 \mathrm{~ns}$ & $1.8 \mathrm{~ns}$ & $0.0 \mathrm{~ns}$ & $2.7 \mathrm{~ns}$ & $0.1 \mathrm{~ns}$ & $0.3 \mathrm{~ns}$ & $0.3 \mathrm{~ns}$ \\
\hline
\end{tabular}

Means $(n=5)$ and SE (inside parentheses) are shown,

Shared letters within each column designate treatments that are not significantly different according to Bonferonni and Scheffé mean comparison tests, "ns" nonsignificant,

${ }^{*} P<.05$,

${ }^{* *} P<.01$,

$* * * P<.001$. 


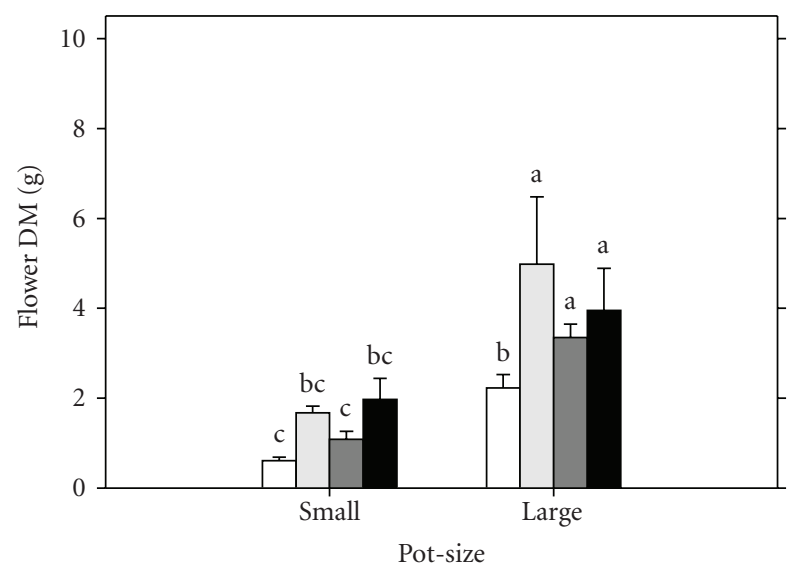

(a)

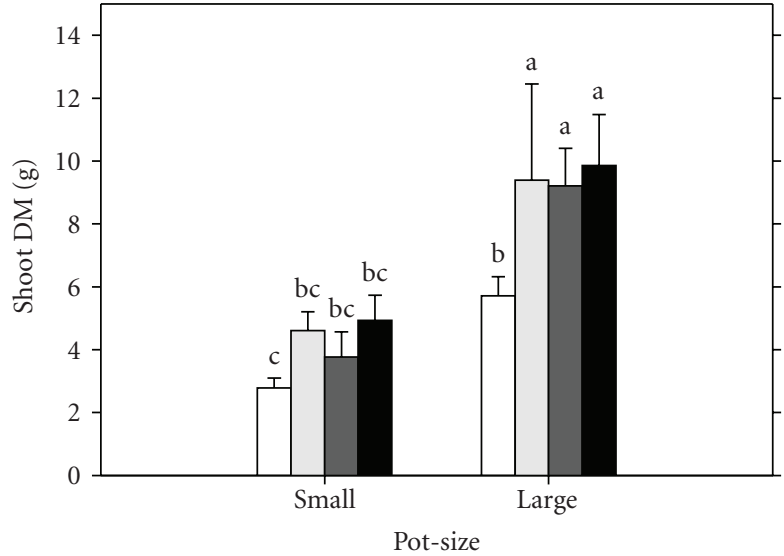

(b)

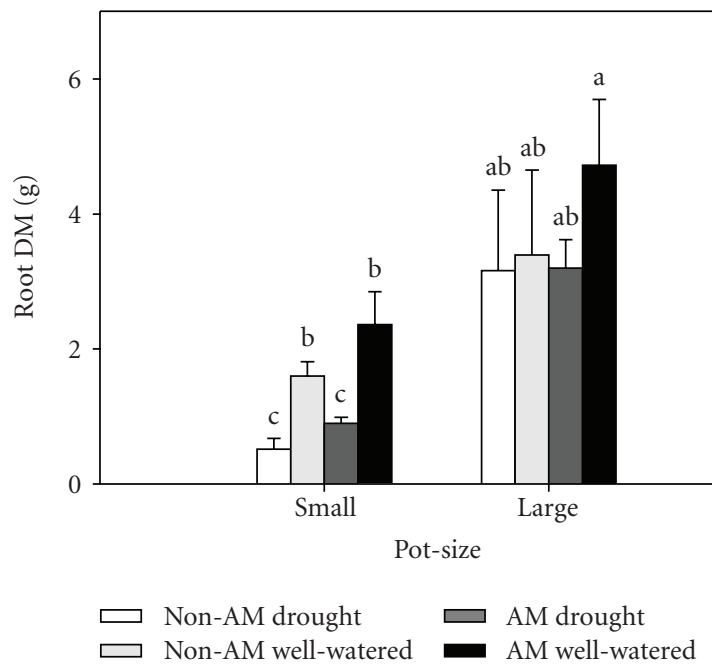

(c)

Figure 3: Flower (a), shoot (b), and root (c) dry masses from the pot size and water deficit experiment. Means $(n=5)$ and SE for the nonAM drought (empty bars), non-AM well-watered (light-grey bars), AM drought (dark-grey bars), and AM well-watered treatments (solid bars) are shown. Shared letters indicate treatments that are not significantly different according to Bonferonni and Scheffé mean comparison tests.

\section{Results}

In the first experiment, the root, shoot, and flower dry masses were over two-fold greater for the large versus small-potted plants (Figure 2); these tendencies also being observed for the fresh masses (data not shown). More specifically, the flower dry mass of large-potted plants (Figure 2(a)) was gradually smaller when comparing the Control $(7.1 \mathrm{~g})$, AMDI ( $4.5 \mathrm{~g})$, and AM-HDL ( $2.8 \mathrm{~g})$ treatments; whereas smallpotted plants (ranging between 0.9 and $1.3 \mathrm{~g}$ ) showed no such significant differences. Although small-potted plant roots showed some incidence of being pot-bound, none of these plants demonstrated any visual signs of nutrient deficiency (data not shown). As for the root colonization (Table 1), all AM plant treatments were shown to be well colonized as evidenced by the presence of hyphae, vesicles, and arbuscules, although the \% frequency and length of root colonization were generally greater among large versus small-potted plants. In addition, the fungal inoculum distribution also influenced root colonization as a greater length of colonization, and density of vesicles were observed for the AM-HDL treatments; yet, a higher density of arbuscules for the AM-DI treatments.

In the second experiment, the root, shoot, and flower dry masses were again greater for the large versus smallpotted plants (Figure 3). The well-watered plants generally produced greater biomass than the drought-treated ones (both large and small pots) which showed symptoms of wilting and chlorosis (data not shown). Notably, the AMdroughted plants grown in large pots showed flower $(3.4 \mathrm{~g})$ and shoot $(9.2 \mathrm{~g})$ dry masses similar to those of well-watered plants ( $4.0 \mathrm{~g}$ flower, $9.9 \mathrm{~g}$ shoot), whereas non-AM droughted plants suffered a reduction in dry mass. The AM-drought small-potted plants showed no such growth advantage over non-AM drought plants. As in the first experiment, all AM plant treatments were well colonized and large-potted plants 
TABLE 2: Root colonization summary for the pot size and water deficit experiment.

\begin{tabular}{|c|c|c|c|c|c|c|c|c|c|}
\hline \multirow[b]{2}{*}{ Pot size } & \multirow[b]{2}{*}{ Irrigation } & \multicolumn{3}{|c|}{ Frequency $(\%)$} & \multicolumn{3}{|c|}{ Root Length Colonized (\%) } & \multicolumn{2}{|c|}{ Density $\left(\mathrm{mm}^{-1}\right)$} \\
\hline & & Hyphae & Vesicles & Arbuscules & Hyphae & Vesicles & Arbuscules & Vesicles & Arbuscules \\
\hline \multirow[t]{2}{*}{ Small } & Drought & $33.6(6.7) \mathrm{a}$ & $24.4(7.1) \mathrm{a}$ & $25.6(4.8) \mathrm{a}$ & $54.0(5.8) \mathrm{b}$ & $22.6(5.2) \mathrm{b}$ & $28.0(1.9) \mathrm{c}$ & $2.6(0.2) \mathrm{b}$ & $3.2(0.1) \mathrm{a}$ \\
\hline & Well-Watered & $40.8(3.0) \mathrm{a}$ & $37.6(4.1) \mathrm{a}$ & $25.2(2.6) \mathrm{a}$ & $76.4(5.1) \mathrm{b}$ & $43.0(3.6) \mathrm{a}$ & $35.7(9.2) \mathrm{bc}$ & $3.2(0.3) \mathrm{a}$ & $3.6(0.4) \mathrm{a}$ \\
\hline \multirow[t]{2}{*}{ Large } & Drought & $44.6(9.7) \mathrm{a}$ & $34.6(9.5) \mathrm{a}$ & $31.0(8.3) \mathrm{a}$ & $71.6(6.1) \mathrm{b}$ & $24.2(5.7) \mathrm{b}$ & $39.5(6.8) b$ & $2.7(0.2) \mathrm{b}$ & $3.5(0.1) \mathrm{a}$ \\
\hline & Well-Watered & $50.8(8.4) \mathrm{a}$ & $38.8(6.2) \mathrm{a}$ & $38.2(7.1) \mathrm{a}$ & $85.2(1.1) \mathrm{a}$ & $30.8(1.3) \mathrm{b}$ & $56.1(2.4) \mathrm{a}$ & $3.4(0.4) \mathrm{a}$ & $3.7(0.1) \mathrm{a}$ \\
\hline \multicolumn{10}{|c|}{ F-values and levels of significance } \\
\hline & Pot size $(\mathrm{P})$ & $1.9 \mathrm{~ns}$ & $0.6 \mathrm{~ns}$ & $2.9 \mathrm{~ns}$ & $6.7^{*}$ & $1.4 \mathrm{~ns}$ & $12.6^{* * *}$ & $0.2 \mathrm{~ns}$ & $1.1 \mathrm{~ns}$ \\
\hline & Irrigation (Ir) & $0.0 \mathrm{~ns}$ & $0.4 \mathrm{~ns}$ & $0.5 \mathrm{~ns}$ & $0.7 \mathrm{~ns}$ & $2.4 \mathrm{~ns}$ & $1.0 \mathrm{~ns}$ & $0.0 \mathrm{~ns}$ & $0.9 \mathrm{~ns}$ \\
\hline & PxIr & $0.8 \mathrm{~ns}$ & $1.4 \mathrm{~ns}$ & $0.4 \mathrm{~ns}$ & $12.3^{* * *}$ & $9.0^{* *}$ & $7.4^{*}$ & $4.4^{*}$ & $1.6 \mathrm{~ns}$ \\
\hline & Block & $0.8 \mathrm{~ns}$ & $0.6 \mathrm{~ns}$ & $2.2 \mathrm{~ns}$ & $0.7 \mathrm{~ns}$ & $0.7 \mathrm{~ns}$ & $4.0^{*}$ & $0.8 \mathrm{~ns}$ & $1.0 \mathrm{~ns}$ \\
\hline
\end{tabular}

Means $(n=5)$ and SE (inside parentheses) are shown,

Shared letters within each column designate treatments that are not significantly different according to Bonferonni and Scheffé mean comparison tests,

"ns" nonsignificant,

${ }^{*} P<.05$,

** $P<.01$,

$* * * P<.001$

again generally tended to have a higher \% frequency and length of root colonization than the small-potted plants (Table 2). Meanwhile, the overall AM root colonization of well-watered plants was greater than drought-treated ones.

\section{Discussion}

We report that pot size is a key experimental factor that, when limiting, can significantly reduce plant growth and AM root colonization. We associate this finding with the fact that the pot is an artificial microcosm having a smaller "rootable" volume than natural environments [4]. This "rootable" volume strictly determines the total nutrient supply in the rhizosphere and then limits the plants' relative growth potential (e.g., \% of maximum growth) without necessarily expressing any noticeable symptoms of nutrient deficiency, as reported with maize, potato, soybean, and young spruce [2-4]. By restricting the proliferation of roots and extraradical hyphae, the "rootable" volume also influences the investment in AM symbiosis since the primary benefit of mycorrhizal association (e.g., an enhanced resource acquisition capacity) is reduced, then resulting in a lower overall root colonization among small-potted plants [1]. Accordingly, when the pot size is less constraining, our results demonstrate that plant growth and AM colonization are both significantly increased.

Besides pot size, we determined that the dispersal of the fungal inoculum further affected AM root colonization such that plants grown in the high density layered (AM-HDL) substrate showed a higher frequency and density of vesicles than those grown in the dispersed inoculum (AM-DI) substrate. By contrast, those grown in the AM-DI substrate showed a higher density of arbuscules. The prevalence of vesicles (sites of lipid storage) over arbuscules (sites of resource exchange) indicates that the AM fungus had reached a more advanced stage of its life cycle [16]. As predicted, this tendency may be attributed to the fact that roots of AM-HDL plants likely had earlier colonization encounters with fungal propagules compared to roots of AM-DI plants which had a relatively more diffuse propagule distribution. For this reason, we suspect that the higher density inoculum distribution could be more effective in promoting root colonization than a dispersed one despite having similar total fungal propagules per pot. Furthermore, we also suspect that such differences in mycorrhizal investment could account for the gradually lower flower dry masses produced by non-AM control, AM-DI, and AM-HDL plants, particularly owing to the differential resource allocation associated with maintaining the symbiosis [17].

From the second experiment, we demonstrated that the pot size effect may confound the dynamics of symbiotic association and plant stress tolerance. Besides having a greater overall biomass and root colonization for the large versus small-potted plants (as above), the AM-droughted plants produced similar shoot and flower biomass compared to the well-watered plants whereas non-AM plants suffered a growth reduction. Unlike small potted-plants which showed no such differences, large potted AM-plants especially benefited from the mycorrhizosphere's enhanced resource acquisition capability which provided them with a significant growth advantage over non-AM plants when subjected to water-deficit conditions $[10,11,17]$. In addition, it is possible that the mycorrhizosphere also provided indirect benefits to host plants by enhancing soil stability $[18,19]$ and moisture retention $[20,21]$ thereby buffering the soil environment. In this regard, a more thorough investigation into the extent of the mycorrhizosphere would be beneficial to specifically verify these perspectives.

In conclusion, this study has shown that pot size and fungal inoculum distribution are key experimental factors that affect plant growth and AM root colonization by respectively influencing (a) the "rootable" volume and (b) the likelihood of interaction between roots and fungal propagules. When limiting, these factors may influence the interpretation of results regardless of the intended experimental conditioning, such as drought resistance. By taking these factors into 
consideration, it is possible to reduce result biases and facilitate the comparison of findings between studies.

\section{Abbreviations}

AM: $\quad$ Arbuscular mycorrhizal

AM-DI: Arbuscular mycorrhizal dispersed inoculum

AM-HDL: Abuscular mycorrhizal high density layered inoculums.

\section{Acknowledgments}

Special thanks are given by the authors to Dr. Zed Rengels (Editor-in-Chief) and the two anonymous evaluators for their insightful review of this manuscript. This study was made possible by a Canada Graduate Scholarship to P.A. and a Discovery Grant to C.C. from the Natural Science and Engineering Research Council of Canada.

\section{References}

[1] E. Bååth and D. S. Hayman, "Effect of soil volume and plant density on mycorrhizal infection and growth response," Plant and Soil, vol. 77, no. 2-3, pp. 373-376, 1984.

[2] G. R. Balali, M. R. Hadi, P. Yavari, H. Bidram, A. G. Naderi, and A. Eslami, "Effect of pot size, planting date and genotype on minituber production of Marfona potato cultivar," African Journal of Biotechnology, vol. 7, no. 9, pp. 1265-1270, 2008.

[3] J. D. Ray and T. R. Sinclair, "The effect of pot size on growth and transpiration of maize and soybean during water deficit stress," Journal of Experimental Botany, vol. 49, no. 325, pp. 1381-1386, 1998.

[4] J. Townend and A. L. Dickinson, "A comparison of rooting environments in containers of different sizes," Plant and Soil, vol. 175, no. 1, pp. 139-146, 1995.

[5] R. T. Koide, "Density-dependent response to mycorrhizal infection in Abutilon theophrasti Medic," Oecologia, vol. 85, no. 3, pp. 389-395, 1991.

[6] L. K. Abbott and A. D. Robson, "Factors influencing the occurrence of vesicular-arbuscular mycorrhizas," Agriculture, Ecosystems and Environment, vol. 35, no. 2-3, pp. 121-150, 1991.

[7] P. Audet and C. C. Charest, "Dynamics of arbuscular mycorrhizal symbiosis in heavy metal phytoremediation: metaanalytical and conceptual perspectives," Environmental Pollution, vol. 147, no. 3, pp. 609-614, 2007.

[8] P. Audet and C. C. Charest, "Allocation plasticity and plantmetal partitioning: meta-analytical perspectives in phytoremediation," Environmental Pollution, vol. 156, no. 2, pp. 290 296, 2008.

[9] P. Audet and C. C. Charest, "Contribution of AM symbiosis to in vitro root metal uptake: from trace to toxic metal conditions," Botany, vol. 87, no. 10, pp. 913-921, 2009.

[10] K. S. Subramanian and C. Charest, "Arbuscular mycorrhizae and nitrogen assimilation in maize after drought and recovery," Physiologia Plantarum, vol. 102, no. 2, pp. 285-296, 1998.

[11] K. S. Subramanian and C. Charest, "Acquisition of $\mathrm{N}$ by external hyphae of an arbuscular mycorrhizal fungus and its impact on physiological responses in maize under droughtstressed and well-watered conditions," Mycorrhiza, vol. 9, no. 2, pp. 69-75, 1999.
[12] F. N. Dalton and M. T. van Genuchten, "The time-domain reflectometry method for measuring soil water content and salinity," Geoderma, vol. 38, no. 1-4, pp. 237-250, 1986.

[13] Y. Dalpé, "Vesicular-arbuscular mycorrhizae," in Soil Sampling and Methods of Analysis, M. R. Carter, Ed., pp. 287-301, CRC Press, Boca Raton, Fla, USA, 3rd edition, 1993.

[14] M. Giovannetti and B. Mosse, "An evaluation of techniques for measuring vesicular-arbuscular mycorrhizal infection in roots," New Phytologist, vol. 84, pp. 489-500, 1980.

[15] J. H. Zar, Biostatistical Analysis, Prentice Hall, Upper Saddle River, NJ, USA, 3rd edition, 1993.

[16] Y. Dalpé, F. A. de Souza, and S. Declerck, "Life cycle of Glomus species in monoxenic culture," in In vitro Culture of Mycorrhizas, S. Declerck, D. G. Strullu, and F. A. Fortin, Eds., pp. 49-71, Springer, Berlin, Germany, 2005.

[17] D. D. Douds, P. E. Pfeffer, and Y. Shachar-Hill, "Carbon partitioning, cost, and metabolism of arbuscular mycorrhizas," in Arbuscular Mycorrhizas: Physiology and Function, Y. Kapulnik and D. D. Douds, Eds., pp. 107-130, Kluwer Academic, Dordrecht, The Netherlands, 2000.

[18] B. N. Bearden and L. Petersen, "Influence of arbuscular mycorrhizal fungi on soil structure and aggregate stability of a vertisol," Plant and Soil, vol. 218, no. 1-2, pp. 173-183, 2000.

[19] R. M. Miller and J. D. Jastrow, "Hierarchy of aggregation," Soil Biology and Biochemistry, vol. 22, no. 5, pp. 579-584, 1990.

[20] R. M. Augé, A. J. W. Stodola, J. E. Tims, and A. M. Saxton, "Moisture retention properties of a mycorrhizal soil," Plant and Soil, vol. 230, no. 1, pp. 87-97, 2001.

[21] J. S. Piotrowski, T. Denich, J. N. Klironomos, J. M. Graham, and M. C. Rillig, "The effects of arbuscular mycorrhizas on soil aggregation depend on the interaction between plant and fungal species," New Phytologist, vol. 164, no. 2, pp. 365-373, 2004. 

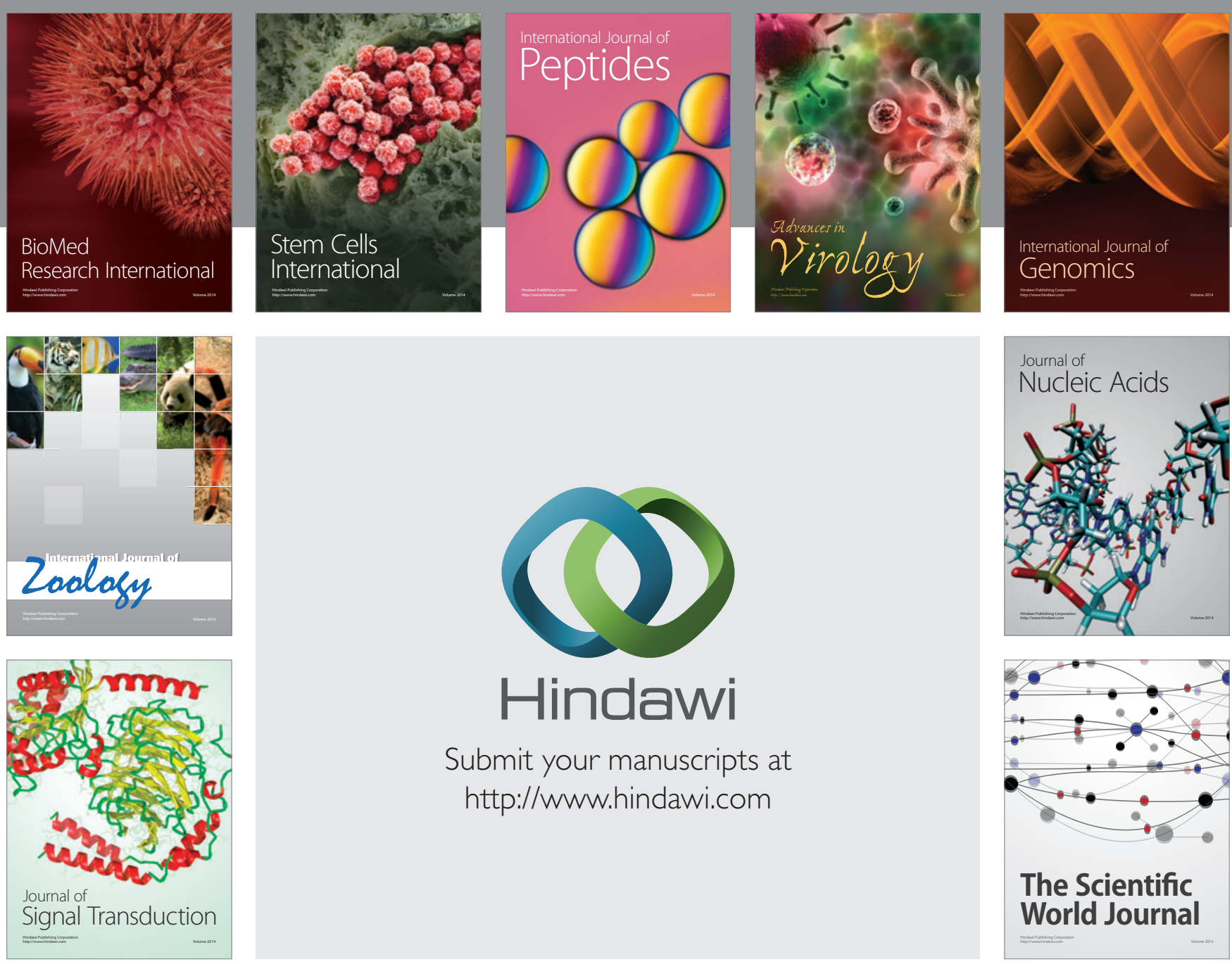

Submit your manuscripts at

http://www.hindawi.com
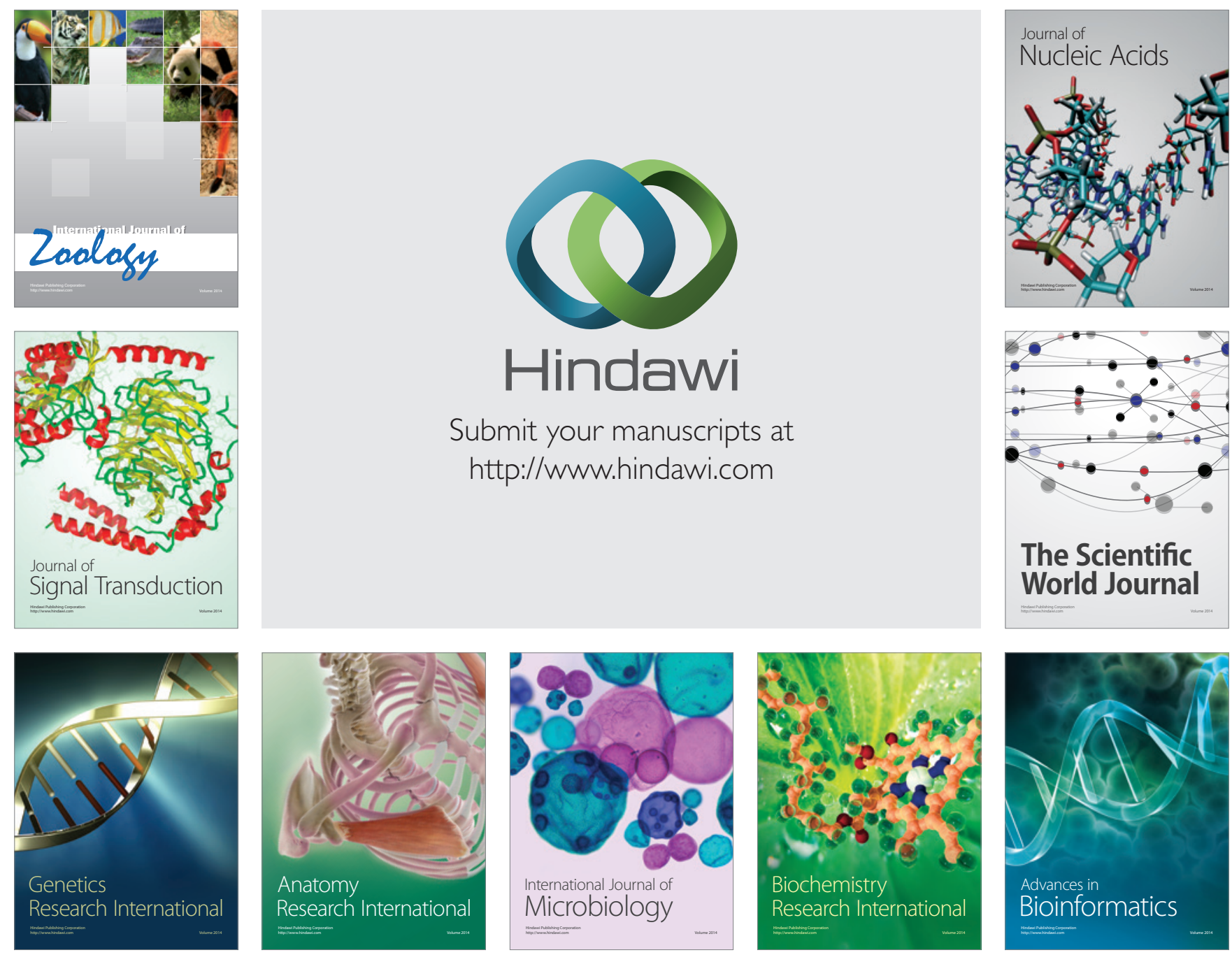

The Scientific World Journal
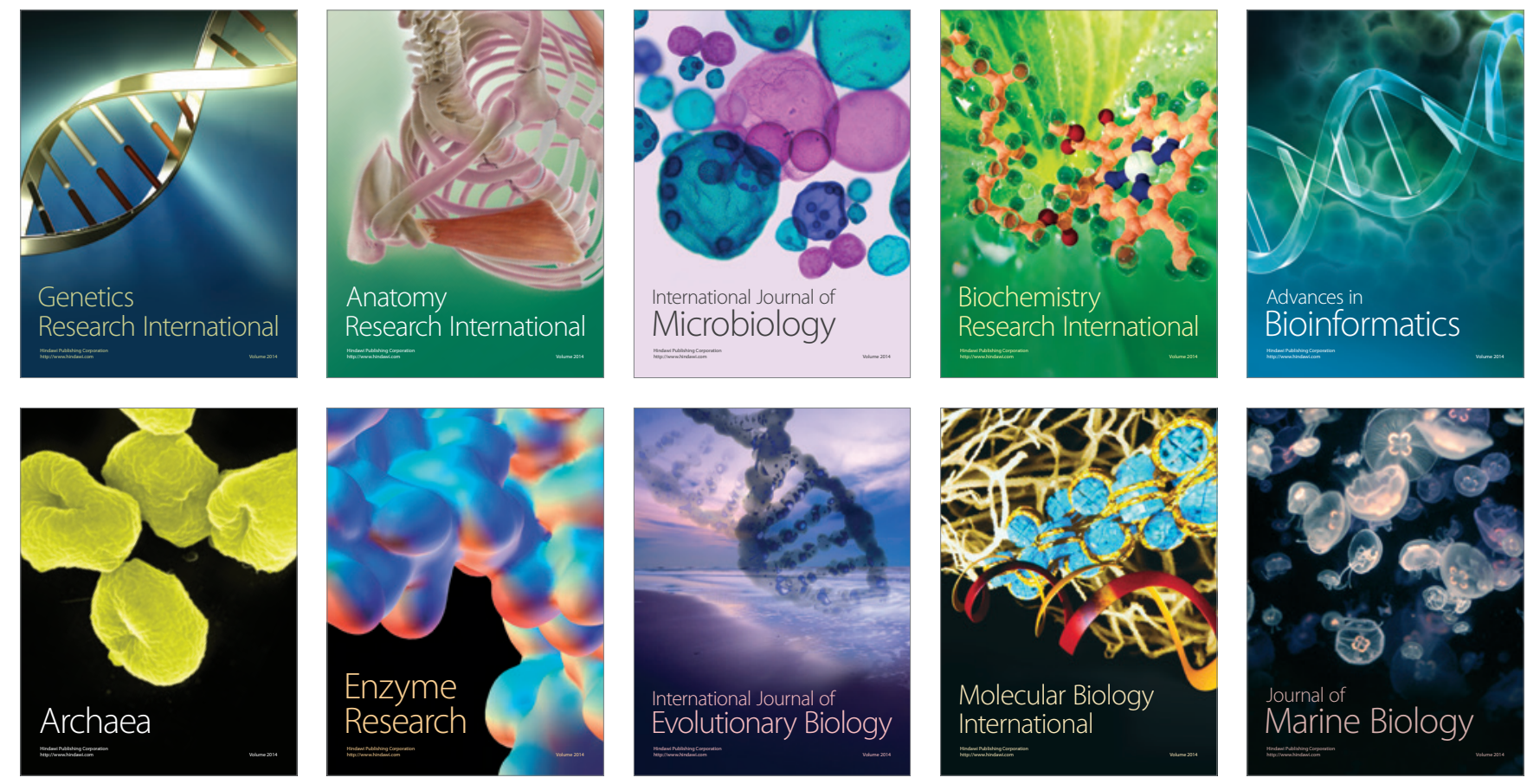